\begin{tabular}{c} 
Brazilian Journal \\
of Chemical \\
Engineering \\
\hline
\end{tabular}

ISSN 0104-6632

Printed in Brazil

www.abeq.org.br/bjche

Vol. 27, No. 04, pp. 591 - 600, October - December, 2010

\title{
ASSESSMENT OF SCD-DP CALIBRATION TO QUANTIFY TRACES OF SULFUR COMPOUNDS IN GASEOUS STREAMS
}

\author{
K. S. Pereira ${ }^{1 *}$, M. C. F. Schmidt ${ }^{2}$ and J. C. Afonso ${ }^{3}$ \\ ${ }^{1}$ PETROBRAS, Centro de Pesquisas Leopoldo Miguez de Mello, \\ Av. Horácio Macedo 950, Sala 456, CEP: 21941-915, Rio de Janeiro - RJ, Brazil. \\ Phone: + (55) (21) 3865 9398, Fax: + (55) (21) 38654894. \\ E-mail: katiapereira@petrobras.com.br \\ ${ }^{2}$ PETROBRAS, Refinaria Duque de Caxias, Laboratório de Qualidade de Produto \\ Rodovia Washington Luiz, Km 113.7, 25225-970, Duque de Caxias - RJ, Brazil. \\ ${ }^{3}$ Instituto de Química, Universidade Federal do Rio de Janeiro. \\ Av. Athos da Silveira Ramos 149, Bloco A, Sala A509, \\ CEP: 21941-909, Rio de Janeiro - RJ, Brazil.
}

(Submitted: February 4, 2010 ; Revised: May 3, 2010 ; Accepted: June 24, 2010)

\begin{abstract}
This work describes the calibration of a gas chromatograph equipped with a sulfur chemiluminescent detector with dual plasma (GC-SCD-DP) for analysis of sulfur-containing petroleum refinery gaseous streams. A packed column in an inert tube (Sulfinert) and an inlet system resistant to reactive sulfur compounds were used. The behavior of the calibration procedure over time depended on the sulfur compound: hydrogen sulfide $\left(\mathrm{H}_{2} \mathrm{~S}\right)$, carbonyl sulfide (COS), methanethiol (MeSH) and dimethylsulfide (DMS) gave constant responses, whereas $\mathrm{SO}_{2}$ presented a systematic increase and dimethyldisulfide (DMDS) showed a systematic decrease of their response factors. In all cases, the response factors were lower than the ones found in the ASTM D 5504-08 method. The GC-SCD-DP technique proved to be a suitable tool for quantification of sulfur compounds (including $\mathrm{SO}_{2}$ ) at $\mu \mathrm{g} \cdot \mathrm{m}^{-3}$ levels in several petroleum refinery gaseous streams.

Keywords: Sulfur compounds; Gas chromatography; Chemiluminescence; Dual plasma.
\end{abstract}

\section{INTRODUCTION}

In the petroleum refining process, the importance of selective and sensitive sulfur detection cannot be underestimated. Sulfur removal from gaseous streams produced in a petroleum refinery depends on the characterization of the sulfur compounds present. This is essential to monitor odor problems, prevent catalyst poisoning and reduce release of $\mathrm{SO}_{2}$ when such streams are burned in flares. The presence of hydrogen sulfide $\left(\mathrm{H}_{2} \mathrm{~S}\right)$ in these streams in considerable amounts poses a health hazard. Its toxicity is a known risk for individuals working in the petroleum, sewer, maritime, and mining industries. It is a broad-spectrum toxicant because it affects most organ systems in the body. $\mathrm{H}_{2} \mathrm{~S}$ exhibits a very steep dose-response relationship with an $\mathrm{LD}_{50}$ of $15 \mathrm{mg} / \mathrm{kg}$ (rats), especially for the central nervous system and respiratory depression, which is the major cause of death in acute $\mathrm{H}_{2} \mathrm{~S}$ poisoning. Neurological and neuropsychiatric squeals have been observed. $\mathrm{H}_{2} \mathrm{~S}$ is a potent inhibitor of cytochrome oxidase (Yalamanchili and Smith, 2008; Lambert et al., 2006; Vale, 2007).

Identification and quantification of sulfur compounds require a suitable analytical procedure (Yan, 2006; Miller and Bruno, 2003). Gas chromatography (GC) is a very powerful technique to identify and quantify sulfur compounds present in gaseous streams. These data allow calculation of

*To whom correspondence should be addressed 
properties like specific gravity and vapor pressure of such streams. In liquid streams, specific gravity data have been used to establish an empirical correlation for in-line estimation of their sulfur content (Pacheco et al., 2009). The on-line analyzer based on ultraviolet fluorescence (UVF) is an analytical technique conceived to determine total sulfur in gaseous streams (Blomberg et al., 2004; Pacheco et al., 2009). GC and the on-line analyzer have their weaknesses and strengths. The GC technique needs special recipients to collect samples and analyses must be performed as soon as possible. The on-line analyzers are subject to elemental sulfur deposition on the UVF system due to constant temperature and pressure changes, thus requiring frequent maintenance.

The main challenge to identify and quantify sulfur compounds in gaseous streams is to develop a reproducible and interference-free analytical method. This is possible by using gas chromatography with a double plasma chemiluminescent detector and a chemically inert system (Sulfinert) for sulfur compounds. Analysis with accuracy at the $\mu \mathrm{g} \cdot \mathrm{m}^{-3}$ level for sulfur compounds is a critical issue. For instance, hydrogen sulfide and sulfur dioxide strongly absorb on metallic surfaces of the injection tubes, generating lower analytical results (Restek, 2005).

Extensive reviews of sulfur chemiluminescence detectors (SCD) for gas chromatography have been published (Gras et al., 2005; Yan, 1999, 2002, 2006; Johansen et al., 2005). There are relatively few reports on the use of SCD with dual plasma (DP) systems for analysis of sulfur compounds in gaseous streams from refineries (Gras et al., 2005). This system may use a packed column in a Sulfinert tube or a megabore column. The first one has two advantages: (i) the detector response is more stable, and (ii) it presents an excellent, accurate analysis at $\mu \mathrm{g} \cdot \mathrm{m}^{-3}$ levels for light sulfur compounds. Comprehensive two-dimensional gas chromatography coupled with fast sulphurchemiluminescence detection appears to be a useful technique to analyze liquid petroleum products (Blomberg et al., 2004, Yan, 2006), but apparently no studies using refinery gaseous streams have been reported.

This study reports calibration of a SCD-DP detector and comparison of the response factors obtained for some sulfur compounds (including sulfur dioxide, $\mathrm{SO}_{2}$ ) with the ones available in the literature (ASTM, 2008). We are also interested in the application of the SCD-DP detector to determine the sulfur compounds present in several gaseous refinery streams. Physical and chemical properties of these compounds are very different. For this reason, two types of calibration mixture were considered: (a) commercially available calibration gas mixtures; (b) calibration gas mixtures obtained via passing a gas (at a known rate) through certified permeation devices.

\section{EXPERIMENTAL}

The high reactivity of sulfur compounds on noninert metallic surfaces tends to reduce the detector response, thus giving lower peak areas than expected. Among the sulfur compounds, $\mathrm{SO}_{2}$ stands out as the most reactive (Pereira, 2006). For this reason, the components in contact with samples must be made of inert materials (like aluminum), or chemically treated to become non-reactive towards sulfur compounds.

\section{Chromatographic System}

The detector used was a SCD-DP from Sievers Research, Inc. (Boulder, Colorado, USA). The injection system consisted of a PTFE (polytetrafluoroethylene) tubing up to the loop inlet, a $1 \mathrm{~mL}$ inert loop (Sulfinert) for sulfur compounds, a valve for automatic gas sampling (jacketed with aluminum) and a valve connection with the column inlet of inert material (Sulfinert) kept at $150^{\circ} \mathrm{C}$. The combustion chamber contained ozone $\left(65 \mathrm{~cm}^{3}\right)$ and hydrogen $\left(45 \mathrm{~cm}^{3}\right)$. Flame temperature was $800^{\circ} \mathrm{C}$. The detector probe pressure was $403-412$ torr.

The packed column used (RT-XL sulfer) contains dimethylpolysiloxane as stationary phase $(2.0 \mathrm{~m} \mathrm{x}$ $0.75 \mathrm{~mm}$ i.d., $100-120$ mesh particle size). According to the literature (Navas and Jiménez, 2000), this column was successful in analysing traces of sulfur compounds in light petroleum distillates using a detector based on the chemiluminescent reaction (SCLD) between hydrogen sulfide $\left(\mathrm{H}_{2} \mathrm{~S}\right)$ and ozone $\left(\mathrm{O}_{3}\right)$.

\section{Standard Reference Materials}

The performance of a calibrated SCD dual plasma was assessed using two types of standard reference material (SRM): (i) a certified compressed gas mixture (cgm) of methanethiol $(\mathrm{MeSH})$ in butane $\left(62.53 \pm 3.13 \mu \mathrm{g} . \mathrm{m}^{-3}\right)$, from White Martins; (ii) certified permeation tubes (VICI Metronics Inc., Poulsbo, Washington, USA - ASTM, 2004, 2005). The device releases the specific sulfur compound through its permeable portion at a constant and known rate following its certificate at a constant temperature $\left(30\right.$ or $\left.40^{\circ} \mathrm{C}\right)$. The permeation tubes used are listed in Table 1. 
Table 1: Types of permeation tubes used in the calibration tests

\begin{tabular}{|c|c|}
\hline Sulfur compound and concentration range $\left(\mu \mathrm{g} \cdot \mathrm{m}^{-3}\right)$ & Type of permeation tube \\
\hline $\begin{array}{l}\text { Hydrogen sulfide }-\mathrm{H}_{2} \mathrm{~S} \\
\text { (from } 1802 \text { to } 6721 \text { ) } \\
\text { (from } 57 \text { to } 71 \text { ) }\end{array}$ & $\begin{array}{l}\text { Extend life tube (ELT-30), } 682 \mathrm{ng} \cdot \mathrm{min}^{-1} \pm 2 \%, 30^{\circ} \mathrm{C} \\
\text { Wafer device (WD-40), } 28.5 \text { ng. } \mathrm{min}^{-1} \pm 5 \%, 40^{\circ} \mathrm{C}\end{array}$ \\
\hline $\begin{array}{l}\text { Carbonyl sulfide }- \text { COS } \\
\text { (from } 1653 \text { to } 3359 \text { ) } \\
\text { (from } 63 \text { to } 82 \text { ) }\end{array}$ & $\begin{array}{l}\text { Wafer device (WD-30), } 641 \mathrm{ng} \cdot \mathrm{min}^{-1} \pm 5 \%, 30^{\circ} \mathrm{C} \\
\text { Wafer device (WD-40), } 227 \mathrm{ng} \cdot \mathrm{min}^{-1} \pm 5 \%, 40^{\circ} \mathrm{C}\end{array}$ \\
\hline $\begin{array}{l}\text { Sulfur dioxide }-\mathrm{SO}_{2} \\
\text { (from } 4121 \text { to } 6753 \text { ) } \\
\text { (from } 87 \text { to 91) }\end{array}$ & $\begin{array}{l}\text { Low emission (LE-30), } 1293 \text { ng. } \mathrm{min}^{-1} \pm 2 \%, 30^{\circ} \mathrm{C} \\
\text { Wafer device (WD-40), } 19.2 \text { ng. } \mathrm{min}^{-1} \pm 5 \%, 40^{\circ} \mathrm{C}\end{array}$ \\
\hline $\begin{array}{l}\text { Methanethiol - MeSH } \\
\text { (from 3581 to } 7770 \text { ) } \\
\text { (from } 2025 \text { to } 2406 \text { ) }\end{array}$ & $\begin{array}{l}\text { High emission (HE-30), } 1113 \text { ng. } \min ^{-1} \pm 2 \%, 30^{\circ} \mathrm{C} \\
\text { Standard device (SD-40), } 335 \text { ng. } \min ^{-1} \pm 2 \%, 40^{\circ} \mathrm{C}\end{array}$ \\
\hline $\begin{array}{l}\text { Dimethylsulfide }- \text { DMS } \\
\text { From } 1048 \text { to } 1324\end{array}$ & Standard device (SD-30), 214 ng. $\min ^{-1} \pm 2 \%, 30^{\circ} \mathrm{C}$ \\
\hline $\begin{array}{l}\text { Dimethyldisulfide - DMDS } \\
\text { From } 1230 \text { to } 1825\end{array}$ & High emission (HE-40), 469 ng. $\min ^{-1} \pm 5 \%, 40^{\circ} \mathrm{C}$ \\
\hline
\end{tabular}

\section{Optimization of the Analytical System}

We aimed at obtaining accurate and precise results at $\mu \mathrm{g} . \mathrm{m}^{-3}$ concentration levels, as well as developing conditions to lower the minimum detectable quantity (MDQ) (Restek, 2005; Chawla and Di Sanzo, 2005; Seung-Wong et al., 1997). In this work, the following parameters were chosen.

\section{$\mathrm{H}_{2} \mathrm{~S}$ and $\mathrm{SO}_{2}$ Responses}

The behavior of the SCD-DP detector was checked by generation of some gas flows containing $\mathrm{H}_{2} \mathrm{~S}$ or $\mathrm{SO}_{2}$ in different concentrations $\left(\mu \mathrm{g} \cdot \mathrm{m}^{-3}\right)$. The correction factors $(\mathrm{CF})$ were compared concerning area repeatability at an acceptable maximum difference of $5 \%$.

\section{Temperature Programming}

Optimal temperature programming conditions must give the best resolution in the shortest analytical run time. The following parameters were investigated: (i) initial temperature $\left(45-60^{\circ} \mathrm{C}\right)$; (ii) heating rate $(1-$ $\left.15^{\circ} \mathrm{C} \cdot \mathrm{min}^{-1}\right)$. Final temperature was $190^{\circ} \mathrm{C}$ and helium $\left(11.3 \mathrm{~mL} \cdot \mathrm{min}^{-1}\right)$ was the gas carrier.

\section{Generation of Sulphur Compounds for Evaluation of the Response Factor}

For sulfur pattern generation from certified permeation tubes, an automatic generation system VICI Metronics Dynacalibrator, model 340 (VICI Metronics Inc., Poulsbo, Washington, USA) was used. Air is pumped though a glass chamber where the certified permeation tubes (from 1 to 6) are placed. A temperature control system sets the temperature mentioned in the tube certificate. According to the sulfur compound concentration desired, an air outflow controller sets the correct flow in a mix chamber. The concentration value $\left(\mu \mathrm{g} \cdot \mathrm{m}^{-3}\right)$ is calculated based on the air outflow used, chamber temperature, room temperature and pressure, molecular weight and sulfur percentage of each sulfur compound used (Asnin et al., 2005).

\section{Calibration of SCD Response}

The calibration method requires quantification by class of sulfur compounds, since the detector response is approximately equimolar for sulfur compounds with the same number of sulfur atoms in the molecule. The quantification was performed by standardizing the concentration of a sulfur compound for each class of interest: thiols, monosulfides, disulfides, $\mathrm{H}_{2} \mathrm{~S}, \mathrm{COS}$ and $\mathrm{SO}_{2}$. All tests were conducted for a range of permeation rate in order to obtain results from a minimum detectable concentration to the highest concentration possible in the permeation tube.

\section{Evaluation of the Combination of Sulfur Compounds}

In order to analyze changes in the SCD response through the correction factors calculated according to ASTM D 5504-08 (ASTM, 2008), calibration was performed using more than one permeation tube in the permeation chamber. Through the combined use of permeation tubes, it was possible to simulate some possible compositions expected in refinery samples, thus performing a calibration under conditions similar to the true samples studied in this work. 


\section{Sulfur Compounds in Refinery Samples}

Seven samples were collected from a refinery sulfur treating plant: (a) residual gas from the sulfur recovery plant (SRP); (b) fuel and (c) residual gases from di-ethanol-amine (DEA) treatment; (d) propane after caustic soda treatment; (e) hydrogen from a hydrotreater (HDT) unit; and (f) natural gas from mono-ethanol-amine (MEA) treatment.

Propane, hydrogen and natural gas were collected using Sulfinert treated stainless steel high pressure sample cylinders $(300 \mathrm{~mL})$. The maximum storage time of these samples was $72 \mathrm{~h}$ to ensure a constant concentration of the sulfur compounds present (Pereira, 2006).

Fuel and residual gases were collected using $1 \mathrm{~L}$ PTFE bags with PTFE tubing. The samples were analyzed within 4 to $8 \mathrm{~h}$ because significant losses of sulfur compounds were observed during long-term storage (Pereira, 2006).

Many sulfur compounds like $\mathrm{H}_{2} \mathrm{~S}$, methanethiol and ethanethiol adsorbed onto metal surfaces. To minimize adsorption phenomena in the sampling point, the samples were taken after purging the line during 30 min to passivate the metal. In the case of sampling residual gas from the sulfur recovery plant, a PTFE tubing inside the transfer line and a PTFE pump to increase the gas flow rate were used. The PTFE tubing inside the transfer lines was different for each sample taken in order to avoid contamination during sampling.

Besides the use of the six sulfur compounds for calibration of the SCD-DP detector, identification of peaks in the chromatograms was performed by using other standard sulfur compounds (1-propanethiol, 2propanethiol and t-butanethiol) and the Kovats retention indexes published in the literature (Miller and Bruno, 2003; Seung-Woon et al., 1997; ASTM, 2008) for 21 sulfur compounds.

\section{RESULTS AND DISCUSSION}

\section{Influence of Temperature on the Elution Sequence}

Initial temperatures lower than $45^{\circ} \mathrm{C}$ led to a broadening of the peakbase due to $\mathrm{H}_{2} \mathrm{~S}$ interaction with the column filling. The peaks corresponding to $\mathrm{H}_{2} \mathrm{~S}$ and carbonyl sulfide (COS) were not well resolved at $60^{\circ} \mathrm{C}$. In order to obtain a good resolution for dimethylsulfide (DMS) and $\mathrm{SO}_{2}$ peaks, the highest possible temperature programming rate was $10^{\circ} \mathrm{C} . \mathrm{min}^{-1}$. Higher rates led to poor resolution of both peaks.

\section{Calibration of the $\mathrm{H}_{2} \mathrm{~S}$ Response}

As shown in Table 2, the extended life tube $\left(\mathrm{H}_{2} \mathrm{~S}-\right.$ 30) presented a better repeatability than the gel mass one $\left(\mathrm{H}_{2} \mathrm{~S}-40\right)$. Discrepancies were not observed for the generation of $\mathrm{H}_{2} \mathrm{~S}$ SRM at either temperature, which is in accord with the frequent use of $\mathrm{H}_{2} \mathrm{~S}$ as reference sulfur compound in the quantitative analysis of other sulfur compounds. Therefore, the correction factor with the extended life tube $\left(\mathrm{H}_{2} \mathrm{~S}\right.$ 30) was taken as the response of $\mathrm{H}_{2} \mathrm{~S}$ at $\mu \mathrm{g} \cdot \mathrm{m}^{-3}$ levels.

\section{Calibration of the COS Response}

The gel mass tube (COS-40) calibrated at $40^{\circ} \mathrm{C}$ presented the best repeatability (Table 2). Another gel mass tube (COS-30), calibrated at $30^{\circ} \mathrm{C}$, presented a median slightly shifted to lower correction factor values. The calculated experimental correction factors were comparable to those published in the ADTM D 5504 standard method (ASTM, 2008), and are clearly different from those of the other sulfur compounds shown in Figure 1.

Table 2: Data set obtained for box-and-whisker plot of the correction factors obtained for $\mathrm{H}_{2} \mathrm{~S}, \mathrm{COS}, \mathrm{MeSH}, \mathrm{SO}_{2}$, DMS and DMDS

\begin{tabular}{|l|c|c|c|c|c|c|}
\hline Sulfur compound & Data points & $\begin{array}{c}\text { Lowest value } \\
\left.\mathbf{( . 1 0}^{-5}\right)\end{array}$ & $\begin{array}{c}\text { Lower quartile } \\
\left(\mathbf{. 1 0}^{-5}\right)\end{array}$ & $\begin{array}{c}\text { CF Median } \\
\left.\mathbf{( . 1 0}^{-5}\right)\end{array}$ & $\begin{array}{c}\text { Upper quartile } \\
\left(\mathbf{. 1 0}^{-5}\right)\end{array}$ & $\begin{array}{c}\text { Highest value } \\
\left(\mathbf{. 1 0}^{-5}\right)\end{array}$ \\
\hline $\mathrm{H}_{2}$ S (ELT-30) & 44 & 4.34 & 4.44 & 4.58 & 4.72 & 4.98 \\
$\mathrm{H}_{2}$ S (WD-40) & 39 & 3.97 & 4.27 & 4.45 & 4.67 & 4.92 \\
COS (WD-30) & 27 & 1.89 & 1.97 & 2.05 & 2.22 & 2.64 \\
COS (WD-40) & 63 & 1.96 & 2.14 & 2.21 & 2.29 & 2.49 \\
MeSH (cgm) & 18 & 3.32 & 3.34 & 3.67 & 3.90 & 4.09 \\
MeSH (HE-30) & 44 & 3.18 & 3.33 & 3.60 & 3.82 & 4.20 \\
MeSH (SD-40) $_{\text {SO }}$ (WD-40) & 62 & 3.26 & 3.94 & 4.43 & 4.59 & 4.89 \\
DMS (SD-30) & 28 & 2.24 & 2.84 & 3.52 & 3.92 & 4.49 \\
DMDS (HE-40) & 40 & 3.18 & 3.35 & 3.40 & 3.62 & 4.02 \\
\hline
\end{tabular}




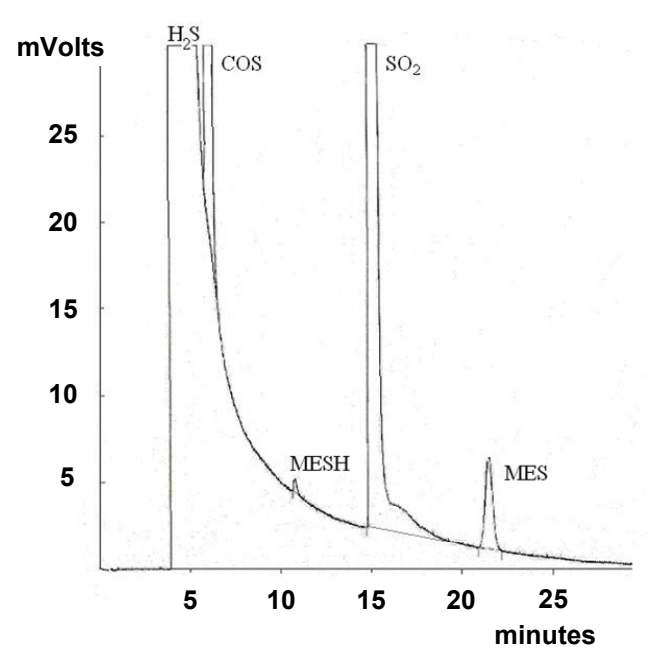

(a)

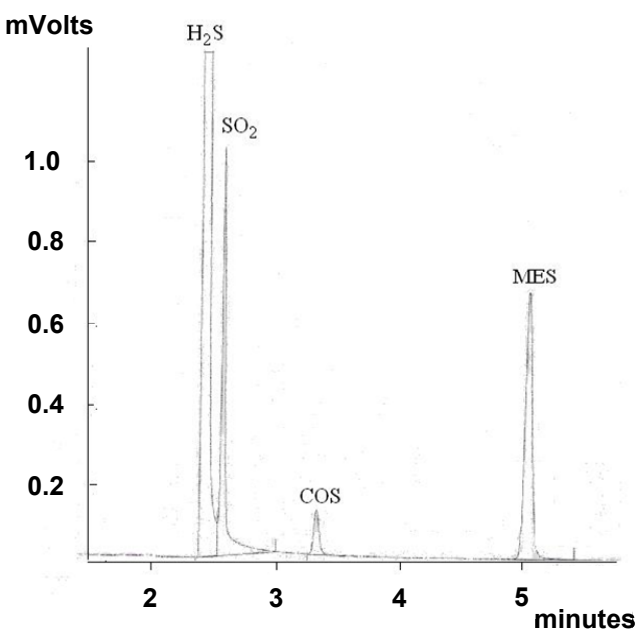

(b)

Figure 1: Sulfur compounds in a SRP residual gas: (a) by SCD-DP with a RT-XL sulfur column in Sulfinert (initial temperature, $45^{\circ} \mathrm{C}$; heating rate, $10^{\circ} \mathrm{C} \cdot \mathrm{min}^{-1}$; final temperature, $190^{\circ} \mathrm{C}$ for $24 \mathrm{~min}$ ); (b) by SCD with a 60 $\mathrm{m} \times 0.53 \mathrm{~mm} \mathrm{HP}-1$ megabore column (loop, $1 \mu \mathrm{L}$; combustion chamber pressure, 35 torr; flame temperature, $780^{\circ} \mathrm{C}$. Initial temperature, $35^{\circ} \mathrm{C}$; heating rate, $5^{\circ} \mathrm{C} \cdot \mathrm{min}^{-1}$; final temperature, $150^{\circ} \mathrm{C}$ for $10 \mathrm{~min}$ ) (Pereira, 2006).

\section{Calibration of the MeSH Response}

The standard emission tube (MeSH-40) originally calibrated at $40^{\circ} \mathrm{C}$ presented a median slightly shifted to higher values and without outliners (Table 2 ). The high emission tube (MeSH-30) originally calibrated at $30^{\circ} \mathrm{C}$ presented a central median and no outliners. When the correction factors calculated for the two distinct types of tubes were compared, a significant difference was noted. This was not verified for the other sulfur compounds (generated by different types of permeation tubes). The variation between the calculated factors for high emission permeation tubes and the ones obtained by calibration with a certified pressurized gas mixture reference in the range of $\mathrm{mg} \cdot \mathrm{m}^{-3}$ was lower than $5 \%$. Thus, the correction factors from high emission permeation tubes were considered for the response of $\mathrm{MeSH}$ at the $\mu \mathrm{g} \cdot \mathrm{m}^{-3}$ level, because it is known that the response is linear over at least three orders of magnitude of concentration (ASTM, 2008).

\section{Calibration of DMS Response}

The experimental correction factors of the standard emission tube (DMS-30) calibrated at $30^{\circ} \mathrm{C}$, were reproducible and comparable to the values published in a standard method (Johansen et al., 2005). As shown in Table 2, the correction factors (CF) are very comparable to the calibration data for DMS generated at $30^{\circ} \mathrm{C}\left(\mathrm{CF}=3.4010^{-5}\right), \mathrm{SO}_{2}$ generated at $40^{\circ} \mathrm{C}\left(\mathrm{CF}=3.5210^{-5}\right)$ and $\mathrm{MeSH}$ generated at $30^{\circ} \mathrm{C}\left(\mathrm{CF}=3.6010^{-5}\right)$.

\section{Calibration of $\mathrm{SO}_{2}$ and DMDS Responses}

As shown in Table 2, the high emission tube of dimethyldisulfide (DMDS) (calibrated at $40^{\circ} \mathrm{C}$ ) and the tube of low $\mathrm{SO}_{2}$ emission (calibrated at $30{ }^{\circ} \mathrm{C}$ ) presented the highest dispersions among the sulfur compounds examined. The median for DMDS was very close to the one for $\mathrm{H}_{2} \mathrm{~S}$, whereas $\mathrm{SO}_{2}$ showed a median near to DMS and MeSH.

From the data in Table 2, it is possible to see the differences among the calculated factors from different sulfur permeation tubes. The criterion applied for discrepancies considers that the variation between the calculated factors for each pair of permeation tubes for the same sulfur compound is not significant when it is less than 5\% (Miller and Miller, 2000).

Calibration of sulfur compounds was performed over 4 months in order to evaluate the response stability of the SCD-DP system. For $\mathrm{H}_{2} \mathrm{~S}, \mathrm{COS}$, $\mathrm{MeSH}$ and DMDS, the detector presented repetitive responses (5\% difference between areas) after 30 min for stabilization of the "flow-through system" without requiring previous passivation. However, a consecutive increase of the response area for $\mathrm{SO}_{2}$ was observed during the first three hours, possibly due to passivation of the chromatographic system. Otherwise a consecutive decrease of the response 
area was observed for DMDS during the first 60 minutes, possibly due to retention by the adsorption column. Thus, $\mathrm{SO}_{2}$ and DMDS SRM calibrations should be performed each time in order to verify whether the calibration factors maintain their previous values. It is advisable to make three preliminary injections before starting $\mathrm{SO}_{2}$ analysis, and one injection in the case of DMDS.

Considering that the median of the SCD response factor for other monosulfur compounds in the calibration step is between $3.0010^{-5}$ and $4.5010^{-5}$, it can be inferred that the system passivation and the adjustment of stabilization time in $\mathrm{SO}_{2}$ pattern generation lead to experimental response factors close to the expected ones, thus confirming that the optimum working conditions were reached. It appears that the time of pattern generation for stabilization of flow and temperature is not as critical as the effect of previous passivation of the system (DMDS and $\mathrm{SO}_{2}$ ). As a result, an increase in the detection signal was observed, thus improving sensibility and lowering the MDQ.

\section{Significance Test for the Calibration Step}

Table 3 shows the comparison of the correction factor calculated using data from the ASTM D 5504 standard method (ASTM, 2008). In virtually all cases, a significant difference was observed (Miller and Miller, 2000). The calculated correction factors were systematically lower than the published ones. The significance test suggests that the SCD-DP inert material column, the inert inlet system and the passivation procedure increased detector response, thus lowering the detection limit for sulfur compounds. In other words, the GC-SCD-DP system under optimized conditions for determination of sulfur compounds in gaseous streams showed higher responses and, consequently, smaller correction factors when compared with those published in the ASTM D 5504 method (ASTM, 2008).

Table 3: Calculated and tabulated correction factors (CF) for $\mathrm{H}_{2} \mathrm{~S}, \mathrm{COS}, \mathrm{MeSH}, \mathrm{SO}_{2}$, DMS and DMDS

\begin{tabular}{|l|c|c|}
\hline Sulfur compound & $\begin{array}{c}\text { Calculated } \\
\left.\text { CF } \mathbf{( . 1 0}^{-5}\right)\end{array}$ & $\begin{array}{c}\text { Tabulated } \\
\left.\text { CF } \mathbf{( . 1 0}^{-5}\right)\end{array}$ \\
\hline $\mathrm{H}_{2} \mathrm{~S}$ & 4.60 & 5.96 \\
$\mathrm{COS}$ & 2.23 & 3.69 \\
$\mathrm{MeSH}$ & 3.61 & 5.01 \\
$\mathrm{DMS}$ & 3.49 & 4.90 \\
$\mathrm{DMDS}$ & 9.05 & 10.00 \\
\hline
\end{tabular}

A comparative test demonstrated that the SCDDP system with a packed column in a Sulfinert tube gives a better accurate analysis at the $\mu \mathrm{g} \cdot \mathrm{m}^{-3}$ level for light sulfur compounds than the traditional SCD system with a megabore column (Pereira, 2006). A typical residual gas sample from a sulfur recovery plant (SRP) was analyzed in the two chromatographic systems: (i) dual plasma with packed column (Figure 1a) and (ii) single plasma with megabore column (Figure 1b). In the first system, it was possible to detect $1 \mu \mathrm{g} \cdot \mathrm{m}^{-3}$ of methanethiol.

Chromatographic data for six sulfur compounds are presented in Table 4. The determination of compound amounts $\left(\mathrm{mg} . \mathrm{m}^{-3}\right)$ was carried out by using the following information in an electronic spreadsheet (Excel): peak name; area (counts); response factor; molecular weight and sulfur percent.

\section{Table 4: Data set obtained for elution time (ET) for some sulfur compounds with helium as carrier gas (11.3 mL.min $\left.{ }^{-1}\right)$ in a SCD-DP with a RT-XL sulfur column in Sulfinert}

\begin{tabular}{|c|c|c|c|c|}
\hline Sulfur compound & $\begin{array}{c}\text { Mean } \\
\text { (ET min) }\end{array}$ & $\begin{array}{l}\text { Highest value } \\
\left(\mathbf{w}^{1 / 2} \mathrm{~min}\right)\end{array}$ & $\begin{array}{l}\text { Upper value } \\
\text { (ET min) }\end{array}$ & $\begin{array}{c}\text { Lower value } \\
\text { (ETmin) }\end{array}$ \\
\hline $\mathrm{H}_{2} \mathrm{~S}($ ELT-30) & 4.143 & 0.198 & 4.190 & 4.075 \\
\hline $\begin{array}{l}\mathrm{H}_{2} \mathrm{~S} \\
\text { (reference sample) }\end{array}$ & 4.999 & 1.884 & 5.371 & 4.626 \\
\hline COS (WD-30) & 5.998 & 0.230 & 6.048 & 5.944 \\
\hline $\mathrm{MeSH}(\mathrm{cgm})$ & 10.057 & 0.403 & 10.097 & 10.008 \\
\hline MeSH (HE-30) & 10.626 & 0.253 & 10.702 & 10.563 \\
\hline DMS (SD-30) & 14.903 & 0.237 & 14.933 & 14.842 \\
\hline $\mathrm{SO}_{2}(\mathrm{cgm})$ & 13.806 & 4.780 & 14.107 & 13.372 \\
\hline $\mathrm{SO}_{2}(\mathrm{WD}-40)$ & 16.180 & 2.045 & 16.656 & 15.970 \\
\hline DMDS (HE-40) & 28.069 & 0.792 & 28.143 & 27.975 \\
\hline
\end{tabular}


Sulfur Compounds in Selected Petroleum Refinery Streams

The analyses were performed under the following conditions: (i) initial temperature, $45^{\circ} \mathrm{C}$; (ii) heating rate, $10^{\circ} \mathrm{C} \cdot \mathrm{min}^{-1}$; (iii) final temperature, $190^{\circ} \mathrm{C}$ for $24 \mathrm{~min}$.

\section{Fuel Gas Samples}

Figure 2 shows the chromatogram of a typical fuel gas sample from distillation of a Brazilian crude oil (Campos Basin) before desulfurization. Nine sulfur compounds were identified. Many of them are present in high concentrations. This leads to a poor resolution of two peaks: ETSH and DMS (peaks 4 and 5); t-butanethiol and s-butanethiol (peaks 7 and 8).

Figure 3 shows the chromatogram of a typical fuel gas sample from distillation of an Arabian crude oil before desulfurization. Fourteen sulfur compounds were found, including three disulfides: DMDS, methyl-ethyldisulfide (MEDS) and diethyldisulfide (DEDS). Only one co-elution was observed (peak 4): ETSH and $\mathrm{SO}_{2}$.

\section{Residual Gas Samples}

Two residual gas samples were analyzed: a sample from FCC (Fluid Catalytic Cracking) after desulfurization using DEA (Figure 4) and after starting a sulfur recovery plant (SRP - Figure 5). In the first case, twelve sulfur compounds were found, $\mathrm{H}_{2} \mathrm{~S}$ and MESH being the major components. The sample from a SRP is much simpler; only five compounds were detected, being present at trace levels $\left(\mu \mathrm{g} \cdot \mathrm{m}^{-3}\right)$. Analysis of this sample is important to adjust the molar ratio between $\mathrm{H}_{2} \mathrm{~S}$ and $\mathrm{SO}_{2}$ in the gas stream when entering the SRP to the best ratio (2:1) (Lieberman, 1991).

\section{Propane Sample}

Figure 6 shows the chromatogram of a typical propane stream after desulfurization with caustic soda. Seven sulfur compounds were identified. The major sulfur compound is DMDS.

\section{Hydrogen and Gas Natural Samples}

Four sulfur compounds were identified in each of these samples. Most of them are present at trace levels $\left(\mu \mathrm{g} \cdot \mathrm{m}^{-3}\right)$. Figure $7 \mathrm{a}$ shows the chromatogram of a typical hydrogen sample after naphtha catalytic reforming. During reforming, $\mathrm{H}_{2} \mathrm{~S}$ readily reacts with air, producing $\mathrm{SO}_{2}$. This explains the higher amount of $\mathrm{SO}_{2}$ found after reforming. The concentration of $\mathrm{H}_{2} \mathrm{~S}$ in the gas natural sample was very low (Figure $7 b)$ because of the desulfurization process with MEA. The three thiols present were deliberately added to allow detection in case of leakage (odorization process). Their concentrations are very close to the amounts added to this sample.

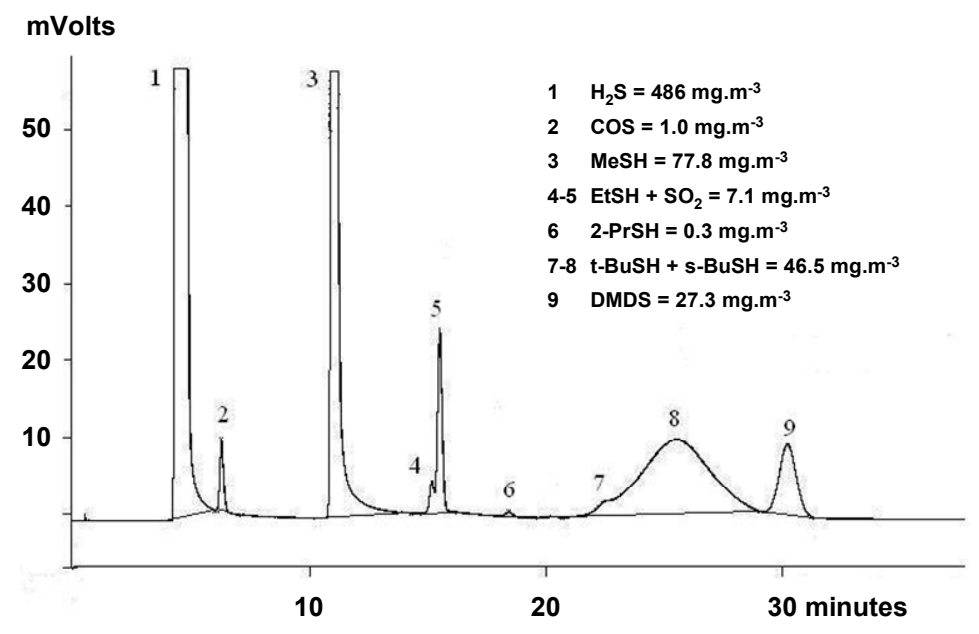

Figure 2: Sulfur compounds in a fuel gas sample from a Brazilian crude oil distillation before desulfurization by SCD-DP with a RT-XL sulfur column in Sulfinert. 


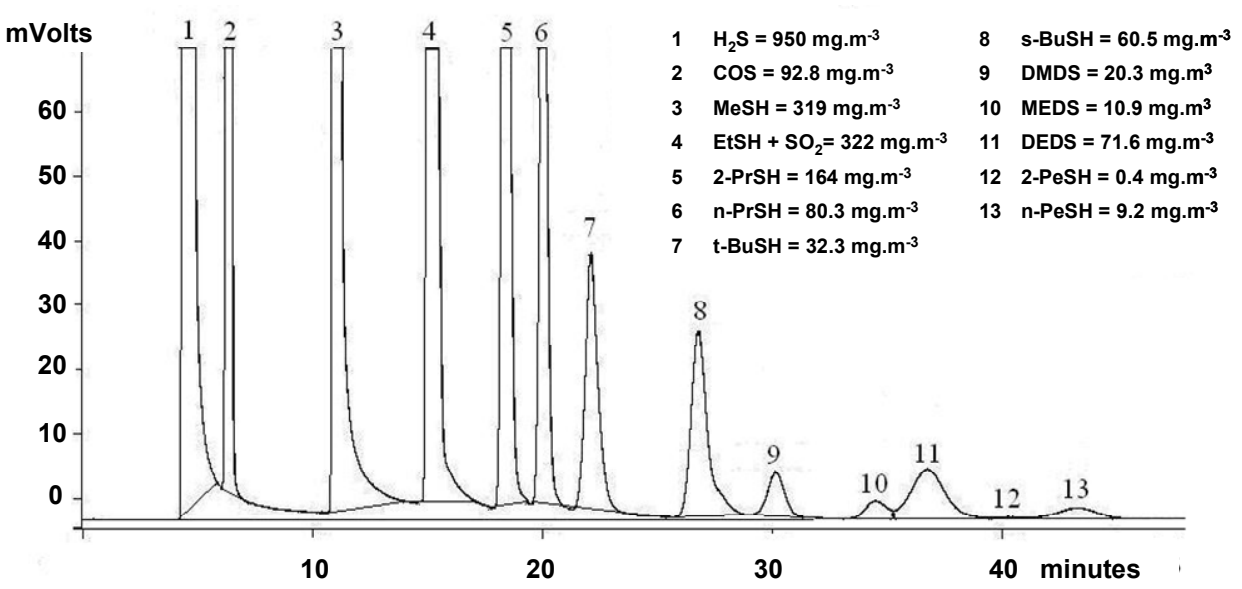

Figure 3: Sulfur compounds in fuel gas sample from an Arabian crude oil distillation before desulfurization, by SCD-DP with a RT-XL sulfur column in Sulfinert

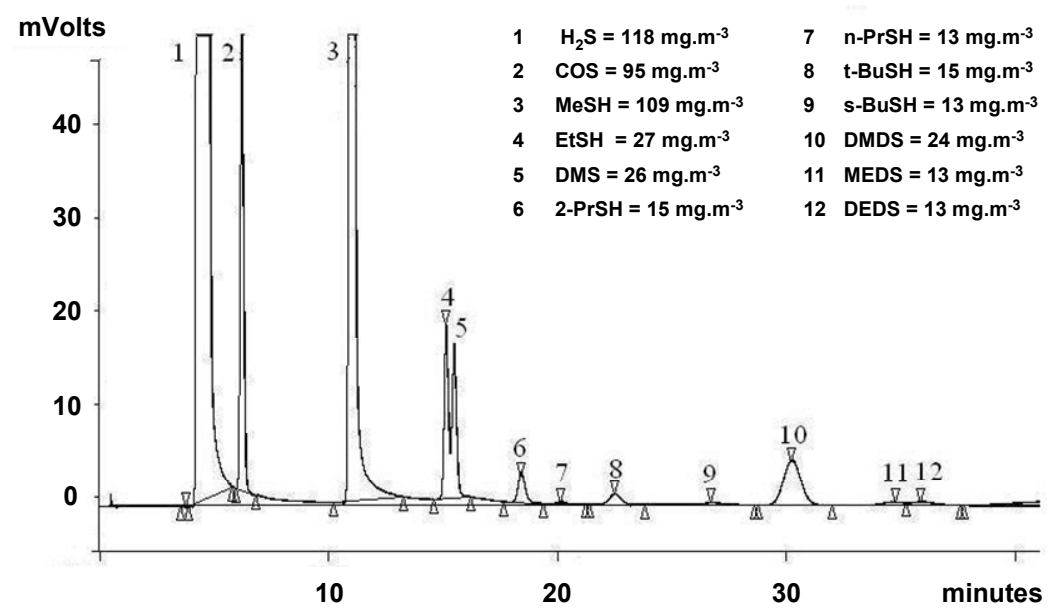

Figure 4: Sulfur compounds in residual gas sample from FCC after desulfurization, by SCD-DP with a RT-XL sulfur column in Sulfinert

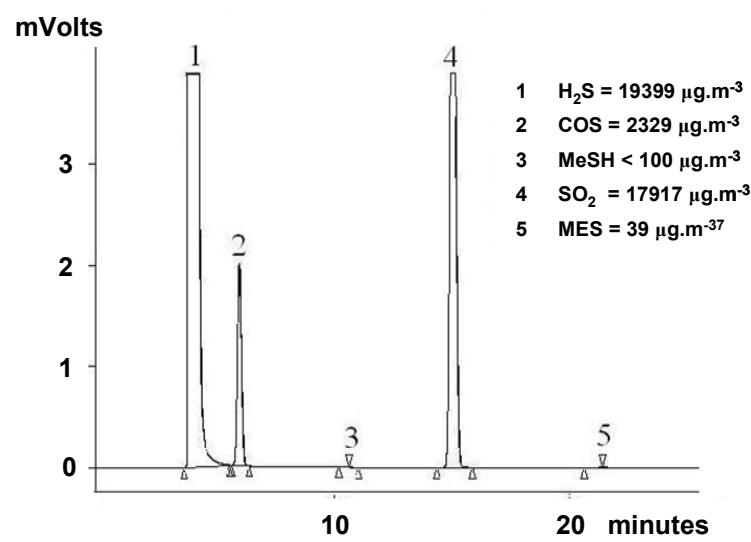

Figure 5: Sulfur compounds in a residual gas sample from SRP by SCD-DP with a RT-XL sulfur column in Sulfinert 


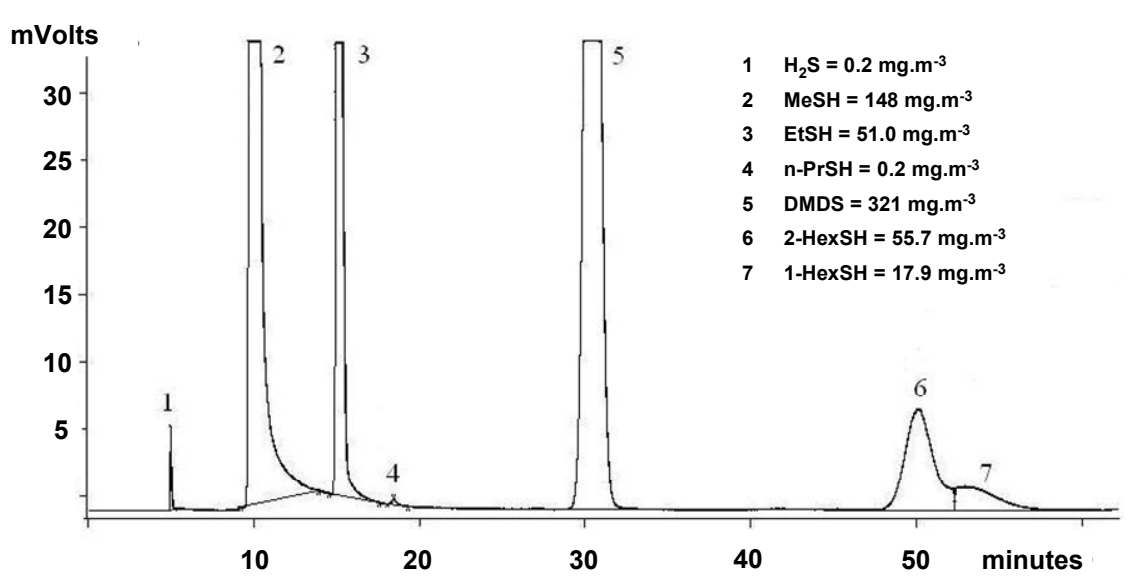

Figure 6: Sulfur compounds in a propane sample after caustic soda treatment, by SCD-DP with a RT-XL sulfur column in Sulfinert

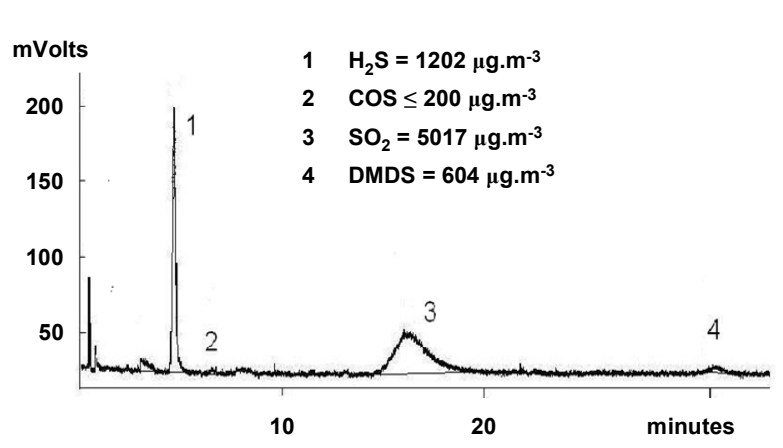

(a)

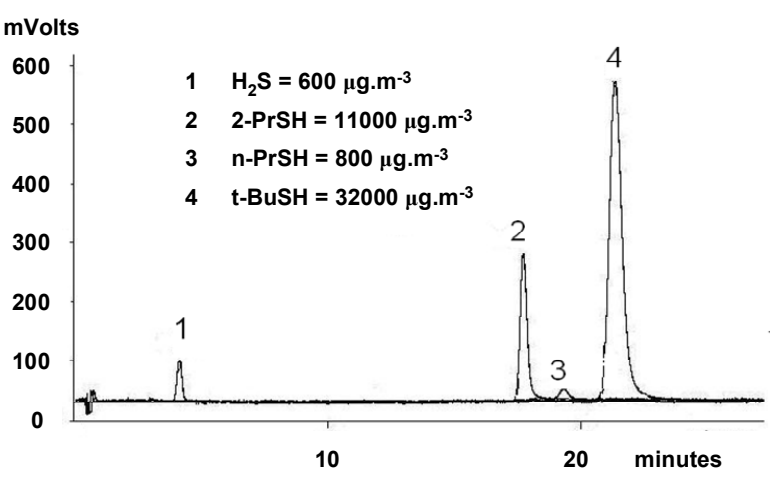

(b)

Figure 7: Sulfur compounds in (a) a hydrogen sample after naphtha catalytic reforming and (b) a natural gas sample after desulfurization with MEA and odorization process, by SCD-DP with a RT-XL sulfur column in Sulfinert.

\section{CONCLUSIONS}

Approximate equimolarity must be considered as a criterion for the analysis of $\mathrm{H}_{2} \mathrm{~S}, \mathrm{COS}$, thiols and sulfides by SCD-DP, since there are differences in the response at the $\mu \mathrm{g} \cdot \mathrm{m}^{-3}$ level. Different types of permeation tubes can lead to different calibration factors for the same sulfur compound, as seen for MeSH.

A critical analysis shows that: (i) there was a systematic difference between the factors calculated and published; (ii) the calculated factors were smaller than the tabulated ones, consequently the response areas of the SCD were higher. This indicates that the detector was optimized for quantification in $\mu \mathrm{g} \cdot \mathrm{m}^{-3}$ levels.

System passivation appears to be more critical than the time of pattern generation for flow stabilization and temperature in the pattern generator in the specific case of $\mathrm{SO}_{2}$ and DMDS. Therefore, a good practice to minimize the analytical error during analysis of $\mathrm{SO}_{2}$ and/or DMDS is to passivate the system with 3 injections of the generated pattern before injecting the sample to be analyzed.

The analytical procedure described in this work was able to quantify sulfur compounds present in a great variety of gaseous streams at $\mu \mathrm{g} . \mathrm{m}^{-3}$ levels. This is of utmost importance for monitoring sulfur removal in the petroleum refinery processes and the quality of finished products.

\section{REFERENCES}

American Society for Testing and Materials, Standard guide for intercomparing permeation tubes to establish traceability. ASTM D 4298 (2004). 
American Society for Testing and Materials, Standard practice for calibration techniques using permeating tubes. ASTM D 3609 (2000, Reapproved 2005).

American Society for Testing and Materials, Standard test method for determination of sulfur compounds in natural gas gaseous fuels by gas chromatography and chemiluminescence, ASTM D 5504 (2008).

Asnin, L., Galinada, W., Götmar, G., Guichon, G., Calibration of a detector for nonlinear chromatography, J. Chromat., A, 1076, p. 141147 (2005).

Blomberg, J., Riemersma, T., van Zuijlen, M., Chaabani, H., Comprehensive two-dimensional gas chromatography coupled with fast sulfurchemiluminescence detection: implications of detector electronics. J. Chromat., A, 1050, p. 7784 (2004).

Chawla, B., Di Sanzo, F., Determination of sulfur components in light petroleum streams by high-resolution gas chromatography with chemiluminescence detection. J. Chromat., A, 589, p. 271-279 (1992).

Gras, R. L., Luong, J. C., Mustacich, R. V., Shearer, R. L., DP-SCD and LTMGC for determination of low sulfur levels in hydrocarbons. Journal of ASTM International, No. 2, issue 7 (2005).

Johansen, N. G., Hutte, R. S., Legier, M. F., A gas chromatography detector based on chemiluminescence for the determination of pesticides. ASTM International Special Technical Publication, STP1102-EB, paper id: STP17899S (2005).

Lambert, T. W., Goodwin, V. M., Stefani, D., Strosher, L., Hydrogen sulfide $\left(\mathrm{H}_{2} \mathrm{~S}\right)$ and sour gas effects on the eye. Sci. Total Environ., 367, p. 122 (2006).

Lieberman, N. P., Troubleshooting process operations. $3^{\text {rd }}$ ed. Penwell Publishing Co., Tulsa (1991).

Miller, K. E., Bruno, T. J., Isothermal Kovats retention indices of sulfur compounds on a poly $(5 \%$ diphenyl-95\% dimethylsiloxane) stationary phase. J. Chromat., A, 1007, p. 117125 (2003).

Miller, J. N., Miller J. C., Statistics and chemometrics for analytical chemistry, $4^{\text {th }}$ ed., Pearson Educational Ltd., Londres (2000).

Navas, M. J., Jiménez, A. M., Chemiluminescent Methods in Petroleum Products. Anal. Chem., 30, p. 153-162 (2000).

Pacheco, M. E., Salim, V. M. M., Pinto, J. C., In-line estimation of sulfur and nitrogen contents during hydrotreating of middle distillates. Braz. J. Chem. Eng., vol. 26, n. 4, pp. 733-744 (2009).

Pereira, K. S., Control of Sulfur Compounds in Petroleum Refinery Gaseous Effluents. M. Sc. Thesis, Federal University of Rio de Janeiro (2006).

RESTEK Performance Coatings, Sulfur Compound Sampling, Storage, and Transfer Considerations Applications Note (2005).

Seung-Woon, M., Soojung, H., Kim, J., Kim, Y., Kim, M., Kim, Y., Kim, W., Kim, B., Gas chromatographic-mass spectrometric analysis of mercaptan odorants in liquefied petroleum gas and liquefied natural gas. J. Chromat. A, 791, p. 367-370 (1997).

Vale, A., Hydrogen sulphide. Medicine, 35, p. 623 (2007).

www.vicimetronics.com (Accessed April, 2010).

Yalamanchili, C., Smith, M. D., Acute hydrogen sulfide toxicity due to sewer gas exposure. Am. J. Emerg. Med., 26, p. 518.e5-518.e7 (2008).

Yan, X., Unique selective detectors for gas chromatography: nitrogen and sulfur chemiluminescence detectors. J. Sep. Sci., 29, p. 1931-1945 (2006).

Yan, X., Sulfur and nitrogen chemiluminescence detection in gas chromatographic analysis. J. Chromat., A, 976, p. 3-10 (2002).

Yan, X., Detection by ozone-induced chemiluminescence in chromatography. J. Chromat., A, 842, p. 267308 (1999). 